\title{
Fate of Cellulose Nanocrystal Aerosols Deposited on the Lung Cell Surface In Vitro
}

\author{
Carola Endes, ${ }^{* \dagger}$ Silvana Mueller, ${ }^{\dagger}$ Calum Kinnear, ${ }^{\dagger}$ Dimitri Vanhecke, ${ }^{\dagger}$ E. Johan Foster, ${ }^{\dagger, \dagger}$ \\ Alke Petri-Fink, ${ }^{\dagger, \$}$ Christoph Weder, ${ }^{\dagger}$ Martin J. D. Clift, ${ }^{\dagger}$ and Barbara Rothen-Rutishauser*, ${ }^{*}$ \\ ${ }^{\dagger}$ Adolphe Merkle Institute, University of Fribourg, Chemin des Verdiers 4, 1700 Fribourg, Switzerland \\ ${ }^{\ddagger}$ Department of Materials Science and Engineering, Virginia Tech, 445 Old Turner Street, 213 Holden Hall, Blacksburg, Virginia \\ 24061, United States \\ ${ }^{\S}$ Department of Chemistry, University of Fribourg, Chemin du Musee 9, Fribourg, Switzerland
}

\begin{abstract}
When considering the inhalation of high-aspect ratio nanoparticles (HARN), the characterization of their specific interaction with lung cells is of fundamental importance to help categorize their potential hazard. The aim of the present study was to assess the interaction of cellulose nanocrystals (CNCs) with a multicellular in vitro model of the epithelial airway barrier following realistic aerosol exposure. Rhodamine-labeled CNCs isolated from cotton (cCNCs, $237 \pm 118 \times 29 \pm 13 \mathrm{~nm}$ ) and tunicate (t-CNCs, 2244

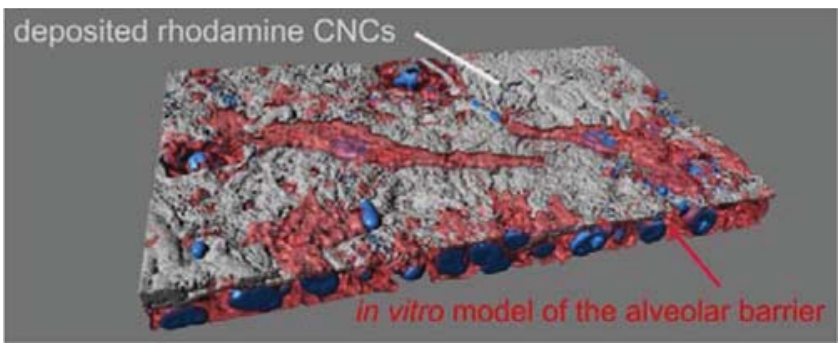
$\pm 1687 \times 30 \pm 8 \mathrm{~nm}$ ) were found to display different uptake behaviors due to their length, although also dependent upon the applied concentration, when visualized by laser scanning microscopy. Interestingly, the longer t-CNCs were found to exhibit a lower clearance by the lung cell model compared to the shorter c-CNCs. This difference can be attributed to stronger fiber-fiber interactions between the t-CNCs. In conclusion, nanofiber length and concentration has a significant influence on their interaction with lung cells in vitro.
\end{abstract}

\section{INTRODUCTION}

Cellulose nanocrystals (CNCs), which can be isolated by acid hydrolysis from many natural sources or even cellulosic waste materials, are increasingly used as a basis for a broad variety of products. $^{1-4}$ CNCs offer benefits to a wide range of applications in different fields of science and technology; they show advantageous characteristics, such as high tensile strength and stiffness, and are thus useful as a filler in high-performance nanocomposites, ${ }^{5,6}$ but are also applicable in mechano-adaptive materials, ${ }^{7,8}$ water purification systems, ${ }^{9}$ and other applications as a cost-effective alternative to carbon nanotubes (CNTs). ${ }^{10}$ Therefore, the universal use of these inexpensive and easy to isolate materials and their consequential mass-scale production is only a matter of time, with a projected production volume of up to 1700 tons of cellulose nanofibers per year by $2017 .^{11}$

Unintended exposure of people to CNCs during production, processing, or disposal of these materials is most likely to occur via inhalation of $\mathrm{CNC}$-containing aerosols. ${ }^{12,13}$ Previously, it has been demonstrated that well-dispersed CNCs isolated from cotton and tunicates (c-CNCs, t-CNCs), when delivered as an aerosol to a three-dimensional in vitro model of the human epithelial airway barrier, elicit no significant negative impact on the cytotoxicity, (pro-)inflammatory response, or oxidative stress status of the cells, even in an overload situation. ${ }^{14}$ These results are in congruence with an earlier study by Clift et al., who found similar results of c-CNCs in submerged exposures toward the same in vitro model in comparison to crocidolite asbestos fibers and multiwalled carbon nanotubes (MWCNTs). ${ }^{15}$ Furthermore, the benign nature of CNCs was shown in a broad ecotoxicological evaluation conducted by Kovacs and co-workers, who tested nanocellulose toward several aquatic trophic levels at environmentally realistic concentrations. ${ }^{16}$ Similar results were obtained by Dong et al., who tested CNCs in suspension against nine different cell lines. ${ }^{17}$ However, the interaction between CNCs and the cellular entity, when considering the lung as a main entry portal into the human body within an occupational setting, is still not fully understood.

The cellular interactions of anisotropic particles is a relatively new field, especially in the case of engineered HARN, which have a nanoscale diameter $(\leq 100 \mathrm{~nm})$ and a much greater length leading to high aspect ratios (ratio of length/diameter). The uptake of single-walled CNTs (SWCNTs) in NIH-3T3 cells has been shown to occur in a length-dependent manner, ${ }^{18}$ as well as the uptake by macrophages and translocation of CNTs into the pleura after inhalation in an overload scenario in vivo. ${ }^{19,20}$ Brown and co-workers showed that long, straight and well-dispersed CNTs caused a higher production of (pro- 
)inflammatory cytokines and reactive oxygen species than curved and entangled samples in vitro, highlighting the importance of fiber dimensions, dispersion state, and fiberfiber interactions. ${ }^{21,22}$ These results were explained with the phenomenon of frustrated phagocytosis, which is well-known for pulmonary exposures to asbestos and has also been shown with long, straight and stiff CNTs. ${ }^{21,23-25}$ This mechanism is induced in a length-dependent manner, with a threshold length of $8 \mu \mathrm{m}$ (diameter $<1.5 \mu \mathrm{m}$ ) for fibrous glass ${ }^{26}$ and $5 \mu \mathrm{m}$ for engineered silver nanowires. ${ }^{27}$ In contrast, the uptake of CNTs is also possible by epithelial cells, which exhibit very limited phagocytic abilities, as well as macrophages, that is, professional phagocytotic cells located at the apical side of the epithelium. ${ }^{28}$ Surprisingly, internalization occurred also independent from energy-mediated uptake mechanisms. ${ }^{29-31}$ Furthermore, it has been observed that the overall uptake rate for anisotropic particles depends on the radius of curvature of the NP at the point of contact with the cell surface, explaining the reduced uptake of higher aspect ratio NPs. ${ }^{32}$ Despite their widespread use, the understanding of the interactions of CNCs with cells is still very limited. Clift and co-workers found CNCs to be present within membrane-bound endosomal structures within monocyte-derived macrophages at the apical side of a triple-cell coculture model featuring epithelial cells, macrophages, and dendritic cells. ${ }^{15}$ Dong et al. showed very low uptake of fluorescently labeled CNCs in RAW 264.7 macrophages only, compared to eight other cell lines, including endothelial and epithelial cell monocultures. ${ }^{33}$ Another study suggests the attachment of CNCs, that is, no internalization, on the cell surface of the algae Chlorella vulgaris after exposure, which is in contrast to MWCNTs that were found in the cytoplasm. ${ }^{34}$ The understanding of $\mathrm{CNC}$-cell interactions, especially within the human alveolar region after inhalation is currently poorly understood.

To close this knowledge gap, the aim of the present study was to investigate the fiber-cell interactions between CNCs extracted from cotton (c-CNCs) and tunicates (t-CNCs), which differ in average length (c-CNCs: $237 \pm 118 \times 29 \pm 13$ nm; t-CNCs: $2244 \pm 1687 \times 30 \pm 8 \mathrm{~nm})$ and aspect ratio. Of special interest was the investigation of the potential uptake and translocation of CNCs across the above-described threedimensional in vitro lung model. To further create a realistic environment for inhalation exposure investigations, relevant doses of rhodamine-labeled CNCs, deduced from permissive exposure limits (PEL) for cotton dusts, ${ }^{35,36}$ were nebulized with the Air-Liquid Interface Cell Exposure System (ALICE), as described previously. ${ }^{14}$ With this approach, the influence of $\mathrm{CNC}$-dimensions on the cellular interactions with an in vitro lung model could be elucidated.

\section{MATERIALS AND METHODS}

Chemicals and Reagents. All reagents and chemicals were obtained from Sigma-Aldrich (Switzerland), unless otherwise mentioned. Deionized, ultrapure water (Sartorius stedim biotech, arium 611DI; Sartorius, Germany) was used in all experiments.

Extraction of Cotton and Tunicate Cellulose Nanocrystals. Cotton cellulose nanocrystals (c-CNCs) were extracted from filter paper (Whatman No.1, Whatman Ltd., England) as previously described by Capadona et al. ${ }^{37}$ who used a modified protocol than the one reported by Dong et al. ${ }^{38}$ Tunicate cellulose nanocrystals ( $\mathrm{t}$ $\mathrm{CNCs}$ ) were isolated from the species Styela clava as published previously. ${ }^{7,8}$

Fluorescent Labeling of CNCs. To enable the visualization of the $\mathrm{CNCs}$ by fluorescence microscopy, their surfaces were functionalized with rhodamine B isothiocyanate (RBITC). The functionalization of both types of CNCs was carried out following exactly the same protocol, except for the initial dispersion procedure. For t-CNCs, $1 \mathrm{~g} \mathrm{t}$ $\mathrm{CNCs}$ that were previously dried at $70{ }^{\circ} \mathrm{C}$ under vacuum overnight were added to $250 \mathrm{~mL}$ of dry dimethylformamide (DMF), so that the $\mathrm{CNC}$ concentration was $4 \% \mathrm{w} / \mathrm{w}$, and a dispersion was prepared by carrying out approximately six alternating cycles of stirring for $30 \mathrm{~min}$ and ultrasonication for $1 \mathrm{~h}$ (Sonoswiss SW3H, Sonoswiss AG, Ramsen, Switzerland; $280 \mathrm{~W}$, room temperature). In the case of cCNCs, $1 \mathrm{~g} \mathrm{c}$-CNCs, also previously dried at $70{ }^{\circ} \mathrm{C}$ under vacuum overnight, were dispersed in dry DMF at a concentration of $4 \% \mathrm{w} / \mathrm{w}$ by $4 \mathrm{~h}$ of ultrasonication.

Functionalization of both CNC types was carried out by adding 0.1 mol equivalent of RBITC to all the glucose monomers and 1 drop of dibutyltindilaurate to the $\mathrm{CNC}$ dispersion, heating the mixture to 100 ${ }^{\circ} \mathrm{C}$, and stirring at this temperature overnight under a $\mathrm{N}_{2}$ atmosphere. Then, the reaction mixture was allowed to cool to room temperature and the modified CNCs were isolated by centrifugation $(7000 \mathrm{rpm}$ for $10 \mathrm{~min}$ ) and decanting. Residual rhodamine and dibutyltindilaurate were removed by 15 steps of dispersion in alternating ethanol, water, centrifugation, and decanting. Finally, the modified $\mathrm{CNCs}$ were dialyzed against water and then freeze-dried. ${ }^{33,39}$ The degree of functionalization of rhodamine-CNCs was determined by UV-vis absorption at a wavelength of $556 \mathrm{~nm}$ following the standard addition procedure. This was carried out by adding known amounts of RBITC to suspensions of functionalized CNCs. To determine the amount of rhodamine attached on the CNCs, the dye concentration in the solutions was plotted against the UV-vis adsorption and the value at the intercept of the resulting graph with the $x$-axis was used as the amount of rhodamine on the CNCs. ${ }^{40}$

Preparation of c-CNCs and t-CNCs Samples. Homogenous and stable suspensions were prepared by dispersing functionalized c-CNCs and $\mathrm{t}$-CNCs at a concentration of $1 \mathrm{mg} / \mathrm{mL}$ in ultrapure water via sonication in a $10 \mathrm{~mL}$ flat bottom glass flask (Duran Schott, Germany) in an Elmasonic P30.H sonication bath (Elma, Hans Schmidbauer GmbH\&CoKG, Singen, Germany) (1 h; frequency $37 \mathrm{kHz}, 100 \%$ intensity, pulse mode). Further dilutions with ultrapure water were carried out immediately, and after the addition of $3.5 \mu \mathrm{L} \mathrm{NaCl}$ (NAAPREP, physiological saline 0.9\%; Glaxo Smith Kline AG, Münchenbuchsee, Schweiz) per $\mathrm{mL}$ of rhodamine-CNC dispersion (end concentration, $500 \mu \mathrm{M}$ ), samples were nebulized with the Air Liquid Interface Cell Exposure system (ALICE) as previously described. ${ }^{14,41}$

Characterization of Rhodamine-Functionalized Cellulose Nanocrystal Suspensions. Transmission Electron Microscopy (TEM). For the TEM characterizations of the rhodamine-c-CNCs and rhodamine-t-CNCs before and after the nebulization process following the protocol published previously, ${ }^{14}$ the procedure by Michen et al. to avoid material aggregation artifacts during drying of the TEM grids was used. ${ }^{42}$ Representative images of all samples were taken using a Hitachi H-7100 (Hitachi, Japan) TEM operated at $75 \mathrm{kV}$ equipped with a Morada 11 MPix digital CCD camera (Olympus, Japan). Lengths and widths of the rhodamine-functionalized CNCs were subsequently analyzed using ImageJ software. ${ }^{43}$ Data presented are representative of 100 individual measurements for each material before and after nebulization, from at least three individual nebulizations (mean \pm standard deviation).

Electrophoretic Mobility. To confirm that the surface functionalization did not change the charge of the CNC surface, the electrophoretic mobility of rhodamine-CNCs in comparison to their nonfunctionalized counterparts was measured with a Brookhaven ZetaPALS (Brookhaven Instruments Corporation, Holtsville, U.S.A.), where the CNCs were dispersed in ultrapure water at a concentration of $1 \mathrm{mg}$ / $\mathrm{mL}$.

Stability. The colloidal stability of rhodamine-CNC dispersions was assessed with a NanoSight NS500 (Nanosight Ltd., Amesbury, United Kingdom) by Nanoparticle Tracking Analysis (NTA). ${ }^{44}$ This technique was used to complement previous stability measurements conducted by depolarized dynamic light scattering (DDLS) of unfunctionalized CNCs. ${ }^{14}$ The dispersed CNCs $(1 \mathrm{mg} / \mathrm{mL})$ were 
Table 1. Key Physico-Chemical Characteristics of Nonfunctionalized and Rhodamine-Functionalized CNCs Derived from Cotton and Tunicates

\begin{tabular}{|c|c|c|c|c|c|c|c|}
\hline \multicolumn{6}{|c|}{ stock solution } & \multicolumn{2}{|l|}{ nebulized } \\
\hline & dimension $(\mathrm{nm})$ & aspect ratio & $\begin{array}{l}\text { functionalization } \\
(\mathrm{mmol} / \mathrm{kg})\end{array}$ & zeta potential & stable & dimension & aspect ratio \\
\hline $\mathrm{c}-\mathrm{CNCs}^{a}$ & $168 \pm 72 \times 19 \pm 7$ & $9 \pm 4$ & & $-26.7 \pm 0.3$ & yes & $161 \pm 61 \times 16 \pm 5$ & $11 \pm 5$ \\
\hline rhodamine-c-CNCs & $237 \pm 118 \times 29 \pm 13$ & $9 \pm 5$ & 21 & $-19.9 \pm 0.4$ & yes & $181 \pm 68 \times 20 \pm 6$ & $10 \pm 7$ \\
\hline $\mathrm{t}-\mathrm{CNCs}^{a}$ & $2331 \pm 1394 \times 31 \pm 7$ & $80 \pm 21$ & & $-22.8 \pm 2.1$ & yes & $2093 \pm 1038 \times 20 \pm 5$ & $108 \pm 57$ \\
\hline rhodamine-t-CNCs & $2244 \pm 1687 \times 30 \pm 8$ & $81 \pm 68$ & 14 & $-27.6 \pm 0.5$ & yes & $1744 \pm 1765 \times 16 \pm 4$ & $115 \pm 123$ \\
\hline
\end{tabular}

diluted 10000 -fold in ultrapure water and loaded into the instrument. Measurements were periodically taken and the mean size was plotted against time, thus indicating the colloidal stability from sonication up to nebulization.

Exposure in the "Air Liquid Interface Cell Exposure System" (ALICE). All in vitro experiments were performed with a coculture model of the epithelial airway barrier of the human lung, ${ }^{45,46}$ as detailed by Lehmann et al. ${ }^{47}$ Additionally, the selection of $\mathrm{CD} 14^{+}$cells was employed, as further described by Steiner et al. ${ }^{48}$ The aerosolization of nanoparticles with the ALICE system was previously published $^{41}$ and recently applied to HARN with the example of unmodified CNCs. ${ }^{14}$ Briefly, $1 \mathrm{~mL}$ of aqueous rhodamine-CNCs suspensions of $0.5 \mathrm{mg} / \mathrm{mL}$ (dose HIGH $_{\text {}}$ ) and $0.1 \mathrm{mg} / \mathrm{mL}$ (dose LOW $_{\text {L }}$ ) in $500 \mu \mathrm{M} \mathrm{NaCl}$ or $\mathrm{NaCl}$ only (negative control) were nebulized and monitored using the integrated quartz crystal microbalance (QCM). Immediately after exposure or the respective postincubation time, cells were fixed for confocal laser scanning microscopy (LSM) or TEM. Postincubation periods $(0,1,24,48 \mathrm{~h})$ at $37{ }^{\circ} \mathrm{C}, 5 \% \mathrm{CO}_{2}$, followed prior to sampling for cytotoxicity measurements and microscopy analyses. Supernatants from the basal side of exposed cells were stored at $4{ }^{\circ} \mathrm{C}$ prior to subsequent analysis.

Cytotoxicity. The release of lactate dehydrogenase (LDH) from the cell lumen was assessed as a measure of cell membrane damage by a LDH cytotoxicity detection kit (Roche Applied Science, Mannheim, Germany) according to the manufacturers protocol. All measurements were carried out in triplicate and evaluated against the negative control. A total of $100 \mu \mathrm{L}$ of $0.2 \%$ Triton $\mathrm{X}_{100}$ in phosphate buffered saline (PBS) was placed on the apical side of the coculture and served as the positive assay control.

Confocal Laser Scanning Microscopy (LSM). For visual examination of the in vitro model exposed to rhodamine-functionalized CNCs, cells were fixed at the respective time points $(0,1,24,48$ h) with Fluorocarbon-72 (FC-72) for 7 min to sustain the deposited CNCs and the liquid lining layer, as shown by Blank et al. ${ }^{45}$ Subsequently, cells were fixed in 4\% paraformaldehyde (PFA) in PBS for $15 \mathrm{~min}$ at room temperature before transferring the samples to 0.1 $\mathrm{M}$ glycine in PBS for $10 \mathrm{~min}$ and stored at $4{ }^{\circ} \mathrm{C}$. Cells were washed three times with PBS and subsequently permeabilized with $0.2 \%$ Triton $\mathrm{X}_{100}$ in PBS for $15 \mathrm{~min}$. Over a period of $2 \mathrm{~h}$, the actin cytoskeleton was then stained with Alexa Fluor 633 phalloidin (Molecular Probes, Life Technologies Europe B.V., Zug, Switzerland) in a 1:100 dilution, and cell nuclei were labeled with $4^{\prime}, 6$-diamidin-2phenylindol (DAPI) at $1 \mu \mathrm{g} / \mathrm{mL}$ in $0.3 \%$ Triton $\mathrm{X}_{100}$ in PBS. Following this, the samples were embedded in Glycergel (DAKO Schweiz AG, Baar, Switzerland). An inverted Zeiss confocal laser scanning microscope 710 (LSM, Axio Observer.Z1) was used to visualize the samples. For each sample, representative images (zstacks) were taken at five random fields of view. Image processing was conducted using the 3D reconstruction software IMARIS (Bitplane AG, Zurich, Switzerland).

Measurement of Translocation and Rhodamine Release. Translocation experiments were carried out with complete supplemented cell media in the basal side without phenol red. Cocultures were transferred to fresh medium containing wells immediately after exposure in the ALICE system. After the respective incubation time, supernatants were collected and measured for their fluorescent intensity at $556 \mathrm{~nm}$ in a table-top fluorescence spectrophotometer using excitation/emission filters of 530/590 nm (TriStar, LB941, Berthold Technologies GmbH\&Co.KG, Bad Wildbad, Germany). To prove the permeability of the used membrane for CNCs, $100 \mu \mathrm{L}$ of 0.1 $\mathrm{mg} / \mathrm{mL}$ CNC suspensions were directly dropped on top of the airliquid interface (ALI) cocultures or empty inserts and analyzed as described above. The fluorescence intensity of a 2 -fold dilution series of both rhodamine-CNCs was measured over a range of $0-250 \mu \mathrm{g} /$ $\mathrm{mL}$ in order to compare their fluorescence to each other.

To probe whether or not the rhodamine dye was cleaved off after exposure or during uptake, fluorescence measurements were conducted in buffers that simulate these respective environments, that is, physiological (extracellular, after deposition) or acidic (intracellular in lysosomes, after uptake). Specifically, rhodamineCNCs were diluted 1:10 in $10 \mathrm{mM}$ sodium phosphate buffer $(\mathrm{pH} 7.4)$ or acetate buffer $(\mathrm{pH} 4.5)$ from the stock $(1 \mathrm{mg} / \mathrm{mL})$ suspension resulting in a final concentration of $0.1 \mathrm{mg} / \mathrm{mL}$. The baseline was taken as the total fluorescence immediately after sonication and dilution. After removal of CNCs by filtration, only free rhodamine dye due to incomplete purification or detachment by sonication was measured ( $0 \mathrm{~h}$ time point in the respective buffer). Removal of CNCs was accomplished by filtering suspensions of $2 \mathrm{~mL}$ with a $0.22 \mu \mathrm{m}$ (Aerodisc $33 \mathrm{~mm}$, PALL AG, Basel, Schweiz) followed by a $0.02 \mu \mathrm{m}$ (Anotop 25, Whatman Ltd., England) syringe filter after 1, 24, 48, and $72 \mathrm{~h}$ incubation resembling exposure times for both materials at both conditions. The results are expressed as a percentage release from the baseline, that is, initial fluorescence measured.

\section{RESULTS}

Characterization of CNCs before and after Nebulization. Well-dispersed rhodamine-functionalized CNCs derived from cotton (rhodamine-c-CNC) or tunicates (rhodamine-t$\mathrm{CNC}$ ) in suspension were characterized for their dimensions, degree of functionalization, electrophoretic mobility, and colloidal stability prior to exposure. In addition, the CNC dimensions after the nebulization process were determined. The characteristics of the CNCs are summarized in Table 1 and are compared to the values of nonfunctionalized CNCs. ${ }^{14}$ After functionalization, rhodamine-CNCs showed dimensions and aspect ratios that showed no significant differences in comparison to their nonfunctionalized counterparts. Figure 1 shows TEM micrographs of rhodamine-c-CNCs (Figure 1a) and rhodamine-t-CNCS (Figure 1b), together with their corresponding length distributions (insets), which were established by quantitative analysis of TEM images.

The respective degree of functionalization with rhodamine on the CNCs was assessed using UV-vis spectroscopy and was slightly higher for c-CNCs $(21 \mathrm{mmol} / \mathrm{kg})$ than for $\mathrm{t}$-CNCs $(14$ $\mathrm{mmol} / \mathrm{kg}$; Table 1 ). This was confirmed by measuring the relative fluorescence units (RFU) of a 2-fold dilution series of the two different $\mathrm{CNC}$ types in a fluorescence plate reader (data not shown). The differences were negligible up to $60 \mu \mathrm{g} /$ $\mathrm{mL}$, which is over 10-fold higher in concentration than any of the exposure scenarios in the present study. Furthermore, 

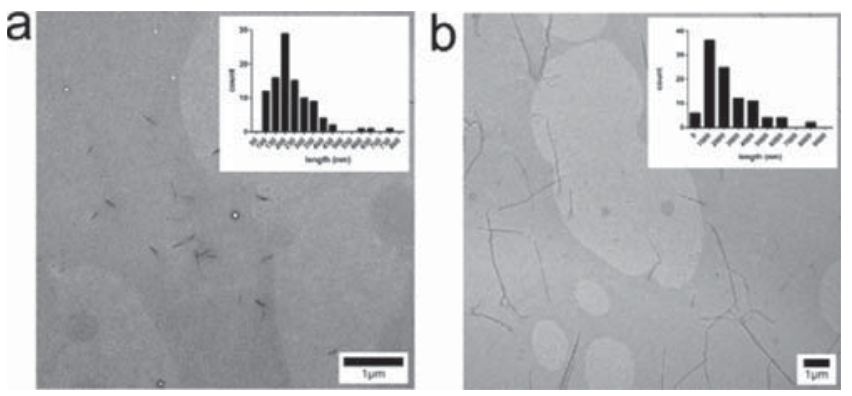

Figure 1. TEM images of rhodamine-c-CNCs (a) and rhodamine-tCNCs (b) cast after sonication in aqueous suspensions. Histograms show length distributions from 100 individual measurements. Scale bars represent $1 \mu \mathrm{m}$.

unchanged electrophoretic mobility and sufficient stability in aqueous suspension were found for both rhodamine-functionalized CNC types (Table 1, Supporting Information, Figure 1).

The nebulization of $1 \mathrm{~mL}$ of CNC suspensions at a concentration of $0.5 \mathrm{mg} / \mathrm{mL}\left(\right.$ dose $\left._{\mathrm{HIGH}}\right)$ resulted in a deposition of $0.56 \pm 0.25 \mu \mathrm{g} / \mathrm{cm}^{2}$ CNCs in the case of rhodamine-c-CNCs and $0.67 \pm 0.09 \mu \mathrm{g} / \mathrm{cm}^{2}$ in the case of rhodamine-t-CNCs. Experiments with a lower dose are discussed below. As shown in Table 1, CNCs deposited onto TEM grids, the dimensions of the nebulized CNCs do not significantly differ from those dimensions of CNCs cast from the stock solutions. Furthermore, the CNCs are homogeneously deposited (Table 1 and Supporting Information, Figure $2)$. This is in congruence with the results obtained for nonfunctionalized CNCs (Table 1), ${ }^{14}$ indicating that the nebulization procedure does not fractionate nor damage the nanocrystals.

Cell Exposure and CNC Clearance. Lung cocultures were exposed to both rhodamine-CNC types via the ALICE system, as described in detail elsewhere. ${ }^{14,41}$ No significant cytotoxicity, as measured by $\mathrm{LDH}$ release, was observed for either material following exposure at the air-liquid interface (Supporting Information, Figure 3a). The purpose of the cytotoxicity measurement was to confirm the absence of nonspecific cytotoxicity of rhodamine-functionalized CNCs toward the in vitro model as we have previously shown for nonfunctionalized CNCs. ${ }^{14}$ These findings were confirmed by LSM, which showed no alterations to cellular morphology over time (Figure 2 and Supporting Information, Figure $4 a-d)$. It is important to note that the epithelial layer condenses over the exposure period, due to multiple cell divisions (cell number increases, cells and nuclei become smaller). This results in the formation of multilayers, a known phenomenon during an extended culturing period at the air-liquid interface ( $>24 \mathrm{~h}$ postexposure; Figure 2 and Supporting Information, Figure 4). ${ }^{45}$

The confocal images in Figure 2 show the distribution of the CNCs deposited, via the ALICE, after nebulization. Individual fibers cannot be spatially resolved due to the resolution limit of sub-100 nm objects, only fiber bundles/aggregates are visible by LSM. Nevertheless, the spatially homogeneous distribution of both deposited $\mathrm{CNC}$ types on the cell surface is readily observed (Figure 2a,e, shadow projections). c-CNCs appear as small fluorescent signals on top of the epithelial cell layer (Figure 2a). After $1 \mathrm{~h}$ postincubation, c-CNCs were present inside single cells of the coculture (Figure $2 b$ ). In addition, subsequent shadow projections of the captured z-stacks show that the morphology of deposited c-CNCs is accumulating in
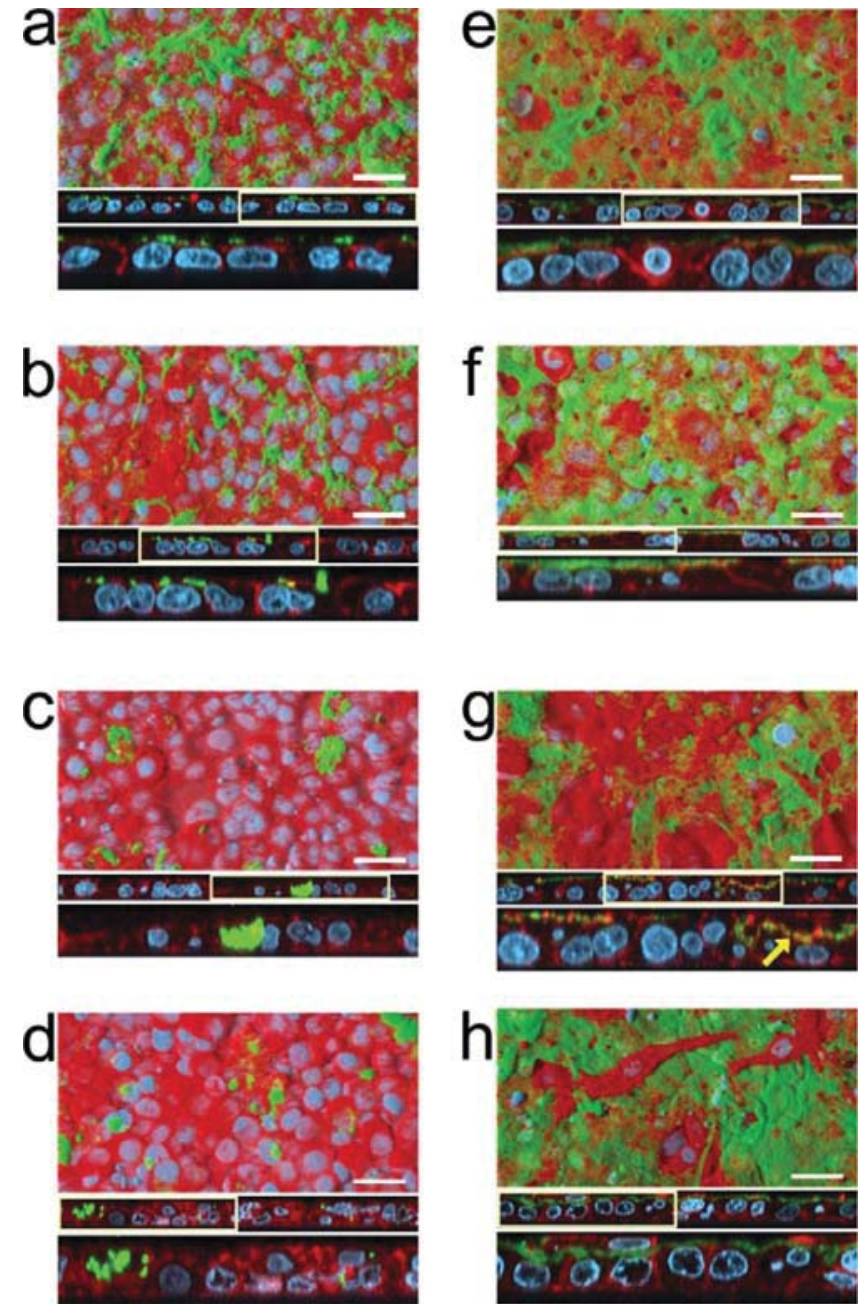

Figure 2. Confocal laser scanning microscopy images of the triple-cell coculture model exposed to $0.56 \pm 0.25 \mu \mathrm{g} / \mathrm{cm}^{2}$ rhodamine-labeled cCNCs (green; a-d) or $0.67 \pm 0.09 \mu \mathrm{g} / \mathrm{cm}^{2} \mathrm{t}$-CNCs $(\mathrm{e}-\mathrm{h})$ via the ALICE system. Cocultures were either immediately fixed (a, e) or after $1(\mathrm{~b}, \mathrm{f}), 24(\mathrm{c}, \mathrm{g})$, or $48 \mathrm{~h}(\mathrm{~d}, \mathrm{~h})$ postexposure and stained for cytoskeleton (red) and nuclei (cyan). Images are presented as surface rendering (top), xz-projection of the z-stacks (middle), or 2-fold optical zoom (bottom). Boxes indicate digitally enlarged $(2 x)$ areas. Arrows show fiber-F-actin interactions. Scale bar $=30 \mu \mathrm{m}$.

"hot-spots" around cells (Figure 2b,c). After 24 and 48 h, respectively, the hot-spot morphology is more prominent and most c-CNCs are cleared from the surface by cells (Figure $2 \mathrm{c}, \mathrm{d})$. In contrast to the $\mathrm{c}-\mathrm{CNCs}$, the $\mathrm{t}$-CNCs form a strong fluorescent, and almost continuous, sheet on top of the cell layer directly after nebulization (Figure 2e). No internalization of $\mathrm{t}$-CNCs was observed after $1 \mathrm{~h}$. Moreover, the $\mathrm{t}$-CNC-sheet appears to shrink in height compared to the directly fixed sample (Figure $2 \mathrm{f}$ ). After 24 or $48 \mathrm{~h}$, the t-CNC-sheet is largely unchanged in coverage and cellular internalization of $\mathrm{t}$-CNCs is rarely observed (Figure $2 \mathrm{~g}, \mathrm{~h}$ ). It is interesting to point out, however, that $\mathrm{t}$-CNCs interact with the apical F-actin-network of the epithelial cells (yellow regions, arrow Figure $2 \mathrm{~g}$ ). In some regions, the cells form an interconnecting network between CNCs and actin filaments or are observed on top of the deposited $\mathrm{t}$-CNC-sheet after $48 \mathrm{~h}$ post exposure (Figure $2 \mathrm{~h}$ ).

To unravel the different interaction phenomena of the two $\mathrm{CNC}$ types, exposures with $\mathrm{CNC}$ suspensions were repeated at a 5-fold lower dose of CNCs. The nebulization of $1 \mathrm{~mL}$ of a 0.1 
$\mu \mathrm{g} / \mathrm{mL}$ rhodamine-CNC-suspensions ( dose $_{\mathrm{LOW}}$ ) resulted in the deposition of $0.14 \pm 0.06 \mu \mathrm{g} / \mathrm{cm}^{2}$ in the case of c-CNCs and $0.13 \pm 0.04 \mu \mathrm{g} / \mathrm{cm}^{2}$ in the case of $\mathrm{t}-\mathrm{CNCs}$, with consistent dimensions and homogeneous deposition (Supporting Information, Figure 2). No cytotoxicity was observed in either exposure scenario compared to the negative control, as determined by $\mathrm{LDH}$ release and morphological analysis via LSM (Supporting Information, Figure 3b and Figure 3). In the
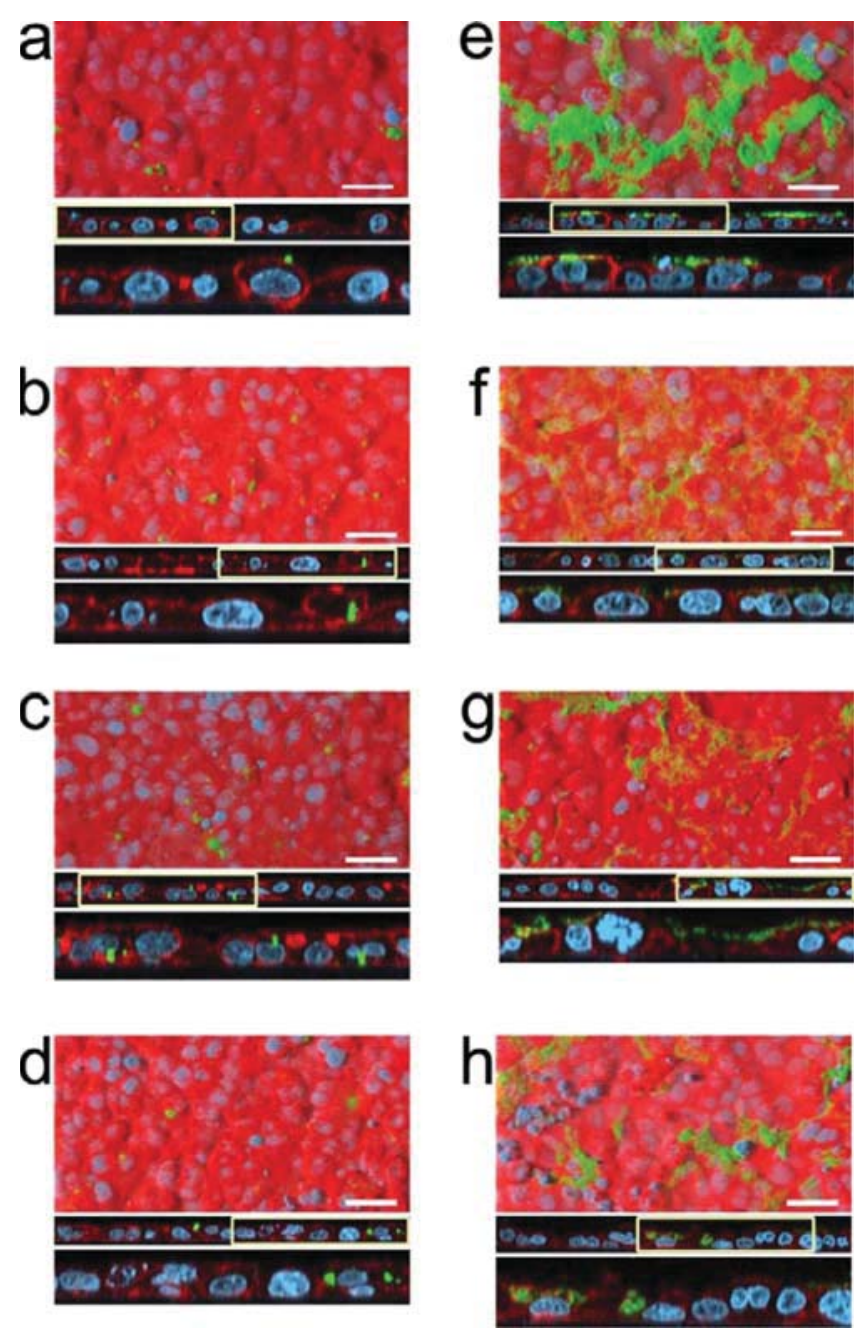

Figure 3. Confocal laser scanning microscopy images of the triple-cell coculture model exposed to $0.14 \pm 0.06 \mu \mathrm{g} / \mathrm{cm}^{2}$ rhodamine-labeled cCNCs (green; a-d) or $0.13 \pm 0.04 \mu \mathrm{g} / \mathrm{cm}^{2} \mathrm{t}-\mathrm{CNCs}(\mathrm{e}-\mathrm{h})$ via the ALICE system. Cocultures were either immediately fixed (a, e) or after $1(\mathrm{~b}, \mathrm{f}), 24(\mathrm{c}, \mathrm{g})$, or $48 \mathrm{~h}(\mathrm{~d}, \mathrm{~h})$ postexposure and stained for cytoskeleton (red) and nuclei (cyan). Images are presented as surface rendering (top), xz-projection of the z-stacks (middle) or 2 -fold optical zoom (bottom). Boxes indicate digitally enlarged $(2 \times)$ areas. Scale bar $=30 \mu \mathrm{m}$.

case of c-CNCs, visualization via LSM revealed that the uptake was similar to the higher dose, suggesting phagocytosis of scavenging macrophages on top of the epithelial surface (Figure $3 a-d)$.

Interestingly, the lower dose of $\mathrm{t}$-CNCs led to a similar uptake pattern, as observed with the shorter c-CNCs (Figure $3 \mathrm{e}-\mathrm{h}$ ). It was noticeable, however, that the $\mathrm{t}-\mathrm{CNCs}$ required a longer postincubation period in order to be taken up by single cells: c-CNCs were readily internalized and observed within cells after $1 \mathrm{~h}$ (Figure $3 \mathrm{~b}$ ), while the internalization of $\mathrm{t}$-CNCs required up to $48 \mathrm{~h}$ (Figure $3 \mathrm{~h}$ ). The formation of fluorescence hot-spots could also be observed with the t-CNCs, but to a lower extent. In contrast to c-CNCs, which were completely cleared, the deposited $\mathrm{t}-\mathrm{CNCs}$ were not entirely removed from the surface of the cell layer within $48 \mathrm{~h}$, which is the longest time point that can be observed in this in vitro system (Figure 3h).

Regarding translocation, no rhodamine-functionalized CNCs were detected in the lower well compartment and monocytederived dendritic cells, which are located at the basal side of the membrane, at all doses tested. This observation was confirmed by LSM (data not shown) and fluorescence measurements of the supernatants at all of the time points investigated (Figure 4 ). In case of the lower dose exposure, the detected values were similar to the limit of quantification (defined as 10x the standard deviation of 10 measurements of water $\left(\mathrm{SD}_{\mathrm{H} 2 \mathrm{O}}\right)$ ).

A rhodamine only control, in which the triple-cell cocultures was exposed to a $100 \mu \mathrm{M}$ rhodamine solution via the ALICE, was conducted for $0,1,24$, and $48 \mathrm{~h}$ post-exposure periods. Fixation occurred as described above. Supporting Information, Figure $4 \mathrm{e}-\mathrm{h}$ shows an overall diffuse rhodamine staining in contrast to the rhodamine-CNC exposed cocultures. Consistent cell morphology, including multilayer formation after $24 \mathrm{~h}$ postexposure can be observed indicative of the absent cytotoxicity.

Nevertheless, an increase in cell size, induced by residual ethanol from the rhodamine stock solution, at $1 \mathrm{~h}$ (Supporting Information, Figure 4f) can be noted, which attenuates after 24 h (Supporting Information, Figure $4 \mathrm{~g}$ ) and disappears after 48 h (Supporting Information, Figure 4h).

In addition, the potential detachment of rhodamine from the functionalized CNCs was investigated over the course of $72 \mathrm{~h}$ under physiological $(\mathrm{pH} 7.4)$ or acidic $(\mathrm{pH} 4.5)$ conditions. In both environments, no detachment of the rhodamine dye from the CNC surface was detected, thus indicating stability of the dye-CNC complex when outside of the cell after nebulization or under acidic conditions, such as in a lysosome, after uptake. An initial level of $\leq 5 \%$ free rhodamine fluorescence was measured for all tested conditions, except rhodamine-t-CNCs, which showed an initial value of $\sim 11 \%$ under neutral conditions. For all conditions and time points tested, no increase in unbound rhodamine could be demonstrated indicating no detachment of the dye due to physiological or acidic conditions during investigation (Figure 5).

\section{DISCUSSION}

Current knowledge regarding CNCs and their potential hazard following human exposure remains limited. The majority of studies, that have considered different types and dimensions of cellulosic fibers or cotton dust ${ }^{16,34,49-59}$ have focused on histology or biochemical end point-based toxicity testing in vivo or in vitro rather than investigating the manner in which CNCs interact with mammalian cells. Therefore, the here presented study focused specifically on the interaction of chemically identical CNCs with two different lengths and at two different exposure doses to obtain a deeper understanding of the fate of CNCs in the lung following inhalation. Using CNCs isolated from natural sources such as cotton or tunicates led to two distinctly different populations in terms of aspect ratio (Table 1). Although some size variations were observed, the frequency/length distribution underlines the significant aspect ratio differences of the two compared CNCs (Figure 1). The 

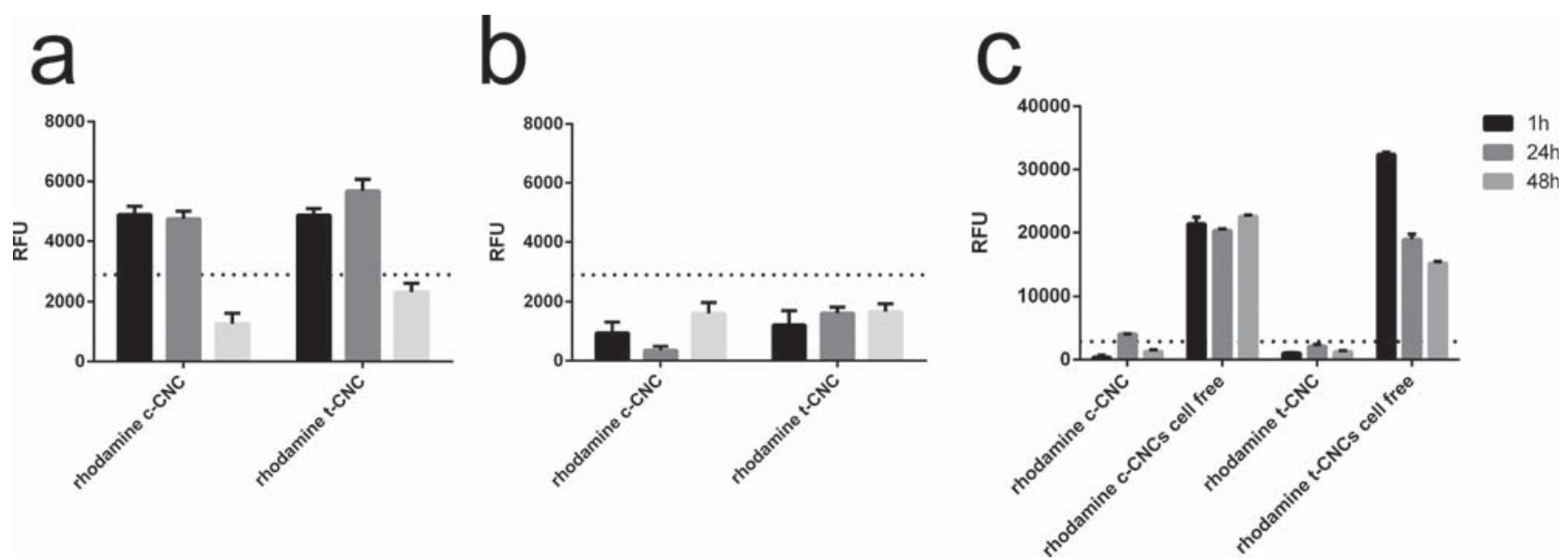

Figure 4. Translocation of rhodamine-CNCs across the epithelial airway barrier in vitro expressed as relative fluorescence units (RFU). Results are presented as corrected values for background fluorescence over time exposed to dose $\mathrm{HIGH}_{\mathrm{H}}\left(0.56 \pm 0.25 \mu \mathrm{g} / \mathrm{cm}^{2}\right.$ for rhodamine-c-CNCs and $0.67 \pm$ $0.09 \mu \mathrm{g} / \mathrm{cm}^{2}$ for rhodamine-t-CNCs) (a) or dose LOW $\left(0.14 \pm 0.06 \mu \mathrm{g} / \mathrm{cm}^{2}\right.$ for rhodamine-c-CNCs and $0.13 \pm 0.04 \mu \mathrm{g} / \mathrm{cm}^{2}$ for rhodamine-t-CNCs) (b). (c) Translocation of CNCs across the inset with or without cells present by directly exposing $100 \mu \mathrm{L}$ of $0.1 \mathrm{mg} / \mathrm{mL}$ of either CNCs at the ALI. The dotted line indicates the limit of quantification $\left(10 \times \mathrm{SD}_{\mathrm{H}_{2} \mathrm{O}}\right)$.

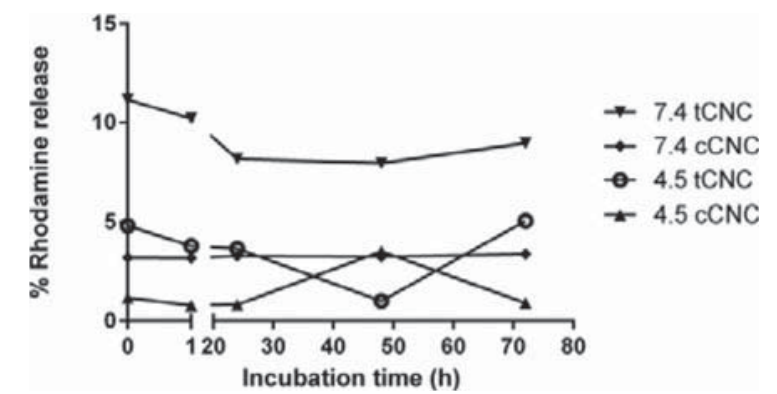

Figure 5. Release of rhodamine from the surface of rhodaminefunctionalized $\mathrm{CNCs}$ under to physiological $(\mathrm{pH} 7.4)$ or acidic conditions ( $\mathrm{pH} 4.5$ ) over time. Results are presented as \% of original functionalization directly after dispersion (i.e., unfiltered). Measured time-points include directly after dispersion, $1,24,48$, or $72 \mathrm{~h}$ after that.

interaction was investigated by fluorescently labeling the CNCs with RBITC, thus enabling their visualization by fluorescence microscopy. Both applied doses represent acute overload scenarios, which could occur due to accidental release of CNCs into the air and, due to the favored deposition of fibers on the bifurcations of prealveolar sacs, the chosen doses can be deemed realistic. Moreover, these doses can be related to the PEL for cotton dust simulating weeks or months of occupational exposure (Occupational Safety and Health Administration (OSHA) cotton dust PEL deduced). ${ }^{35,36}$

The results presented here highlight the necessity of using realistic exposure scenarios for the investigation of inhalation hazard assessment of HARN with an air-liquid system combined with advanced 3D in vitro cultures. ${ }^{14}$ Notably, the epithelial type II A549 cells in the coculture system have been shown to produce an aqueous lining layer, ${ }^{45}$ which can influence the fate of deposited fibers and particles due its composition of phospholipoproteins and proteins. ${ }^{60}$ Whereas protein/surfactant-rich environments are usually favorable to raise the stability of nanofiber dispersions, ${ }^{61,62}$ the surfactant constituents on top of epithelial cells can form a size-exclusion mesh-like structure interfering with the fiber-cell interactions. The nebulization with the ALICE system deposits an aqueous layer of circa $14 \mu \mathrm{m}$ in height (assuming a deposition efficiency of $\sim 57 \%$, droplets of $5 \mu \mathrm{m}$ mass median diameter) on top of the surfactant film. ${ }^{14,41}$ Under these conditions, the shorter cCNCs can diffuse freely due to their dimension without contacting adjacent fibers within this layer and therefore interaction and uptake by cells is more probable and energetically favorable. In contrast, the longer t-CNCs cannot rotate freely and are more likely to come into contact with neighboring fibers within this thin layer. Due to this increased interaction, fiber-fiber attraction forces (predominantly hydrogen bonds for cellulosic fibers) are more dominant and lead to bundling and structures with increased dimensions. ${ }^{63,64}$ From a biological stance, these structures could become immobilized by the surfactant mesh, offering an extended fiber-network structure that challenge or prevent $\mathrm{CNC}$ uptake. These structural formations would explain the strong F-actin interactions observed in $\mathrm{t}-\mathrm{CNC}$ exposed cells hindering uptake. After exposure of the lung coculture model at the air-liquid interface to two different $\mathrm{CNC}$ doses, distinct differences in the uptake kinetics between c-CNCs and $\mathrm{t}$-CNCs were observed. High doses of short c-CNCs were readily cleared from the surface by internalization within $24 \mathrm{~h}$ post exposure, whereas longer t-CNCs remained as a deposited sheet on top of the cell layer up to $48 \mathrm{~h}$. This situation was altered when the dose was lowered 5-fold. In this scenario, t-CNCs are partially removed from the surface of the cells during the postexposure period ( 48 $\mathrm{h})$, but to a significantly less extent compared to c-CNCs. In all cases of successful uptake (dose $\mathrm{HIGH}_{\mathrm{H}}$ and dose $_{\mathrm{LOW}} \mathrm{c}$-CNCs, dose $_{\text {LOW }}$ low t-CNCs), macrophages present at the apical side of the coculture, scavenging the surface of the epithelial layer, are presumably responsible for removal of CNCs from the epithelial surface. Additionally, the theory of fiber assembly prior to uptake by macrophages is supported by the clustering of CNCs into hot-spot like structures. ${ }^{18}$ The finding that CNCs can be internalized into macrophages, however, is consistent with the study by Clift et al., where nonfunctionalized CNCs isolated from cotton were used in an submerged exposure scenario and found within a macrophage endosome using electron tomography. ${ }^{15}$ Furthermore, in a study conducted with nebulized MWCNTs, it was shown that after $24 \mathrm{~h}$ postexposure of a single dose $\left(0.14-0.39 \mu \mathrm{g} / \mathrm{cm}^{2}\right)$, MWCNT were mainly found in macrophages of the same coculture model that was 
employed in the present study. ${ }^{65}$ It is noted that while longerterm effects of materials retained in the lung would be important to study, the cell model employed here is limited to be used over a period of 3 days; therefore further studies would be necessary to be performed in vivo.

Despite the observed uptake of c-CNCs and $\mathrm{t}-\mathrm{CNCs}$ into cells of the coculture in this study, no translocation, as a clearance pathway across the barrier, was detectable by fluorescence measurements or LSM (data not shown) for any of the materials at the doses or time points tested (Figure 4). It is worth noting that (i) the confluent and dense epithelial layer structure was preserved, and (ii) the fibers alone are able to pass the inset membrane (i.e., when no cells are present on the inset) (Figure 4c). These observations suggest the removal of $\mathrm{CNCs}$ from the coculture surface occurs via active processes, potentially through the scavenging ability of immune cells (i.e., macrophages), which is a valuable insight when considering the long-term consequences of $\mathrm{CNC}$ exposure to humans.

In addition, another key advantage of the present study is that it demonstrates the importance of the visualization of CNC-cell interactions on a micrometer scale via surfaceattached fluorophores and fluorescence imaging. Dong and colleagues have shown cellular uptake after exposure to fluorescently labeled CNCs solely in the read-out of a fluorescent plate reader without visualizing the $\mathrm{CNC}-$ cell interaction. ${ }^{17}$ Mahmoud et al. showed uptake of FITC or rhodamine functionalized flax-derived CNCs depending on their surface charge. ${ }^{66}$ However, due to the lack of sufficient microscopic analysis in 3D, the observed fluorescence could also stem from CNCs attachment to the outer cell membrane. Although the fluorescent read-out of cell lysates after exposure confirms the microscopic interpretation, insufficient data of cell viability and morphology as well as no characterization of the fluorescence stability depending on $\mathrm{pH}$ means the results of this study is disputable. ${ }^{66}$ Furthermore, it has to be emphasized that the physicochemical characteristics of a CNC sample strongly influences the biological outcome. Yanamala et al. showed varying inflammatory responses, cytotoxicity, and oxidative stress induced by pharyngeal aspiration exposure to CNCs in mice either as dispersions of the gel (CNCS) or powder form (CNCP) after 24 h. ${ }^{59}$ The two preparation techniques used led to significant differences in mean lengths $\left(\mathrm{CNCS}_{\mathrm{TEM}} 90 \pm 3\right.$ $\mathrm{nm} ; \mathrm{CNCP}_{\mathrm{TEM}} 208 \pm 49 \mathrm{~nm}$ ) and according to the authors to the different outcome observed. Therefore, the study highlights the difference in biological response upon pulmonary exposure to CNCs in different dimensions. This is comparable with the presented findings where the length of $\mathrm{CNCs}$ is the main driving force for rapid ( $\mathrm{c}-\mathrm{CNCs}$ ) or slow ( $\mathrm{t}-\mathrm{CNCs}$ ) removal from the epithelial surface.

\section{CONCLUSIONS}

The outcome of the present study shows the dominating influence of fiber dimension on the clearance mechanism after inhalation and deposition in the lung. This was accomplished by functionalizing and characterizing $\mathrm{CNCs}$ with a fluorescent label (rhodamine B) thus enabling the visualization of CNCs with LSM. The rhodamine-labeled CNCs were delivered to an in vitro model of the human epithelial airway barrier in a realistic scenario for inhalation exposure. In order to understand the possible risk of CNC exposure by inhalation, it is indispensable to consider their retention time in the lung. As indicated above, the long $\mathrm{t}$-CNCs cannot be completely cleared from the apical surface of the cell layer within the investigated time period, which might lead to long-term consequences. However, the results within the sensible time frame of the in vitro model are limited in reflecting the in vivo situation where clearance can occur more slowly than $48 \mathrm{~h}$ postexposure. By contrast, c-CNCs are readily engulfed and cleared from the cell surface. Taking into consideration the fiber-fiber interaction, the dimensions of the mesh network, and the limited clearance by cells of this tissue region, the potential hazard of these nanomaterials has to be further evaluated.

In conclusion, the aspect ratio in combination with deposited dose of CNCs strongly influences the uptake by a 3D coculture system of the human epithelial airway barrier in vitro under realistic conditions due to occurring fiber-fiber interactions. These findings emphasize the potential implications concerning human exposure to long HARN, such as t-CNCs.

\section{ASSOCIATED CONTENT}

S Supporting Information

Additional information for control experiments and rhodamineCNC characterization.

\section{AUTHOR INFORMATION}

\section{Corresponding Authors}

*E-mail: carola.endes@unifr.ch.

*E-mail: barbara.rothen@unifr.ch.

\section{Notes}

The authors declare no competing financial interest.

\section{ACKNOWLEDGMENTS}

The authors wish to thank the Swiss National Science Foundation (National Research Programme 64, Project \#406440 131264/1) and the Adolphe Merkle Foundation for financial support. E.J.F. would like to thank P3Nano for support.

\section{REFERENCES}

(1) Eichhorn, S. J. Cellulose Nanowhiskers: Promising Materials for Advanced Applications. Soft Matter 2011, 7, 303-315.

(2) Habibi, Y.; Lucia, L. A.; Rojas, O. J. Cellulose Nanocrystals: Chemistry, Self-Assembly, and Applications. Chem. Rev. 2010, 110, 3479-3500.

(3) Johar, N.; Ahmad, I.; Dufresne, A. Extraction, Preparation and Characterization of Cellulose Fibres and Nanocrystals from Rice Husk. Ind. Crop Prod. 2012, 37, 93-99.

(4) van den Berg, O.; Capadona, J. R.; Weder, C. Preparation of Homogeneous Dispersions of Tunicate Cellulose Whiskers in Organic Solvents. Biomacromolecules 2007, 8, 1353-1357.

(5) Tang, L.; Weder, C. Cellulose Whisker/Epoxy Resin Nanocomposites. ACS Appl. Mater. Interfaces 2010, 2, 1073-1080.

(6) Favier, V.; Chanzy, H.; Cavaille, J. Y. Polymer Nanocomposites Reinforced by Cellulose Whiskers. Macromolecules 1995, 28, 63656367.

(7) Jorfi, M.; Roberts, M. N.; Foster, E. J.; Weder, C. Physiologically Responsive, Mechanically Adaptive Bio-Nanocomposites for Biomedical Applications. ACS Appl. Mater. Interfaces 2013, 5, 1517-1526.

(8) Shanmuganathan, K.; Capadona, J. R.; Rowan, S. J.; Weder, C. Stimuli-Responsive Mechanically Adaptive Polymer Nanocomposites. ACS Appl. Mater. Interfaces 2010, 2, 165-174.

(9) Ma, H.; Hsiao, B. S.; Chu, B. Ultrafine Cellulose Nanofibers as Efficient Adsorbents for Removal of $\mathrm{UO}_{2}{ }^{2+}$ in Water. ACS Macro Lett. 2012, 1, 213-216.

(10) Eichhorn, S. J.; Dufresne, A.; Aranguren, M.; Marcovich, N. E.; Capadona, J. R.; Rowan, S. J.; Weder, C.; Thielemans, W.; Roman, M.; Renneckar, S.; Gindl, W.; Veigel, S.; Keckes, J.; Yano, H.; Abe, K.; 
Nogi, M.; Nakagaito, A. N.; Mangalam, A.; Simonsen, J.; Benight, A. S.; Bismarck, A.; Berglund, L. A.; Peijs, T. Review: Current International Research into Cellulose Nanofibres and Nanocomposites. J. Mater. Sci. 2010, 45, 1-33.

(11) Future Markets Inc. The global market for nanocellulose to 2017. Technology Report No. 60; http://www.futuremarketsinc.com/ the-global-market-for-nanocellulose-to-2024/.

(12) Hagens, W. I.; Oomen, A. G.; de Jong, W. H.; Cassee, F. R.; Sips, A. J. A. M. What Do We (Need to) Know about the Kinetic Properties of Nanoparticles in the Body? Regul. Toxicol. Pharmacol. 2007, 49, 217-229.

(13) Maynard, A. D.; Kuempel, E. D. Airborne Nanostructured Particles and Occupational Health. J. Nanopart. Res. 2005, 7, 587-614.

(14) Endes, C.; Schmid, O.; Kinnear, C.; Mueller, S.; CamareroEspinosa, S.; Vanhecke, D.; Foster, E.; Petri-Fink, A.; RothenRutishauser, B.; Weder, C.; Clift, M. An In Vitro Testing Strategy Towards Mimicking the Inhalation of High Aspect Ratio Nanoparticles. Part. Fibre Toxicol. 2014, 11, 40.

(15) Clift, M. J. D.; Foster, E. J.; Vanhecke, D.; Studer, D.; Wick, P.; Gehr, P.; Rothen-Rutishauser, B.; Weder, C. Investigating the Interaction of Cellulose Nanofibers Derived from Cotton with a Sophisticated 3D Human Lung Cell Coculture. Biomacromolecules 2011, 12, 3666-3673.

(16) Kovacs, T.; Naish, V.; O’Connor, B.; Blaise, C.; Gagne, F.; Hall, L.; Trudeau, V.; Martel, P. An Ecotoxicological Characterization of Nanocrystalline Cellulose (NCC). Nanotoxicology 2010, 4, 255-270.

(17) Dong, S.; Hirani, A. A.; Colacino, K. R.; Lee, Y. W.; Roman, M. Cytotoxicity and Cellular Uptake of Cellulose Nanocrystals. Nano LIFE 2012, 02, 1241006.

(18) Jin, H.; Heller, D. A.; Sharma, R.; Strano, M. S. Size-Dependent Cellular Uptake and Expulsion of Single-Walled Carbon Nanotubes: Single Particle Tracking and a Generic Uptake Model for Nanoparticles. ACS Nano 2009, 3, 149-158.

(19) Mercer, R.; Scabilloni, J.; Hubbs, A.; Wang, L.; Battelli, L.; McKinney, W.; Castranova, V.; Porter, D. Extrapulmonary Transport of MWCNT Following Inhalation Exposure. Part. Fibre Toxicol. 2013, 10,38 .

(20) Ryman-Rasmussen, J. P.; Cesta, M. F.; Brody, A. R.; ShipleyPhillips, J. K.; Everitt, J. I.; Tewksbury, E. W.; Moss, O. R.; Wong, B. A.; Dodd, D. E.; Andersen, M. E.; Bonner, J. C. Inhaled Carbon Nanotubes Reach the Subpleural Tissue in Mice. Nat. Nanotechnol. 2009, 4, 747-751.

(21) Brown, D. M.; Kinloch, I. A.; Bangert, U.; Windle, A. H.; Walter, D. M.; Walker, G. S.; Scotchford, C. A.; Donaldson, K.; Stone, V. An In Vitro Study of the Potential of Carbon Nanotubes and Nanofibres to Induce Inflammatory Mediators and Frustrated Phagocytosis. Carbon 2007, 45, 1743-1756.

(22) Rothen-Rutishauser, B.; Brown, D. M.; Piallier-Boyles, M.; Kinloch, I. A.; Windle, A. H.; Gehr, P.; Stone, V. Relating the Physicochemical Characteristics and Dispersion of Multiwalled Carbon Nanotubes in Different Suspension Media to Their Oxidative Reactivity in Vitro and Inflammation in Vivo. Nanotoxicology 2010, 4, 331-42.

(23) Donaldson, K.; Murphy, F. A.; Duffin, R.; Poland, C. A. Asbestos, Carbon Nanotubes and the Pleural Mesothelium: A Review of the Hypothesis Regarding the Role of Long Fibre Retention in the Parietal Pleura, Inflammation and Mesothelioma. Part. Fibre Toxicol. 2010, 7, 5.

(24) Dodson, R. F.; Atkinson, M. A. L.; Levin, J. L. Asbestos Fiber Length As Related to Potential Pathogenicity: A Critical Review. Am. J. Ind. Med. 2003, 44, 291-297.

(25) Poland, C. A.; Duffin, R.; Kinloch, I.; Maynard, A.; Wallace, W. A. H.; Seaton, A.; Stone, V.; Brown, S.; MacNee, W.; Donaldson, K. Carbon Nanotubes Introduced into the Abdominal Cavity of Mice Show Asbestos-Like Pathogenicity in a Pilot Study. Nat. Nanotechnol. 2008, 3, 423-428.

(26) Stanton, M. F.; Layard, M.; Tegeris, A.; Miller, E.; May, M.; Kent, E. Carcinogenicity of Fibrous Glass: Pleural Response in the Rat in Relation to Fiber Dimension. J. Natl. Cancer Inst. 1977, 58, 587603.

(27) Schinwald, A.; Murphy, F.; Prina-Mello, A.; Poland, C.; Byrne, F.; Glass, J.; Dickerson, J.; Schultz, D.; Movia, D.; Jeffree, C.; MacNee, W.; Donaldson, K. The Threshold Length for Fibre-Induced Acute Pleural Inflammation: Shedding Light on the Early Events in AsbestosInduced Mesothelioma. Toxicol. Sci. 2012, 128, 461-470.

(28) Lohmann-Matthes, M. L.; Steinmüller, C.; Franke-Ullmann, G. Pulmonary Macrophages. Eur. Respir. J. 1994, 7, 1678-1689.

(29) Ali-Boucetta, H.; Al-Jamal, K. T.; Muller, K. H.; Li, S.; Porter, A. E.; Eddaoudi, A.; Prato, M.; Bianco, A.; Kostarelos, K. Cellular Uptake and Cytotoxic Impact of Chemically Functionalized and PolymerCoated Carbon Nanotubes. Small 2011, 7, 3230-8.

(30) Al-Jamal, K. T.; Nerl, H.; Muller, K. H.; Ali-Boucetta, H.; Li, S.; Haynes, P. D.; Jinschek, J. R.; Prato, M.; Bianco, A.; Kostarelos, K.; Porter, A. E. Cellular Uptake Mechanisms of Functionalised MultiWalled Carbon Nanotubes by 3D Electron Tomography Imaging. Nanoscale 2011, 3, 2627-35.

(31) Lacerda, L.; Russier, J.; Pastorin, G.; Herrero, M. A.; Venturelli, E.; Dumortier, H.; Al-Jamal, K. T.; Prato, M.; Kostarelos, K.; Bianco, A. Translocation Mechanisms of Chemically Functionalised Carbon Nanotubes Across Plasma Membranes. Biomaterials 2012, 33, 333443.

(32) Florez, L.; Herrmann, C.; Cramer, J. M.; Hauser, C. P.; Koynov, K.; Landfester, K.; Crespy, D.; Mailänder, V. How Shape Influences Uptake: Interactions of Anisotropic Polymer Nanoparticles and Human Mesenchymal Stem Cells. Small 2012, 8, 2222-2230.

(33) Dong, S. P.; Roman, M. Fluorescently Labeled Cellulose Nanocrystals for Bioimaging Applications. J. Am. Chem. Soc. 2007, 129, 13810-13811.

(34) Pereira, M.; Mouton, L.; Yepremian, C.; Coute, A.; Lo, J.; Marconcini, J.; Ladeira, L.; Raposo, N.; Brandao, H.; Brayner, R. Ecotoxicological Effects of Carbon Nanotubes and Cellulose Nanofibers in Chlorella vulgaris. J. Nanobiotechnol. 2014, 12, 15.

(35) Endes, C.; Müller, S.; Schmid, O.; Vanhecke, D.; Foster, E. J.; Petri-Fink, A.; Rothen-Rutishauser, B.; Weder, C.; Clift, M. J. D. Risk Assessment of Released Cellulose Nanocrystals - Mimicking Inhalatory Exposure. J. Phys.: Conf. Ser. 2013, 429, 012008.

(36) OSHA Occupational Safety and Health Standards. Cotton dust; https://www.osha.gov/pls/oshaweb/owadisp.show_document?p_id= 10053\&p_table $=$ STANDARDS.

(37) Capadona, J. R.; Van Den Berg, O.; Capadona, L. A.; Schroeter, M.; Rowan, S. J.; Tyler, D. J.; Weder, C. A Versatile Approach for the Processing of Polymer Nanocomposites with Self-Assembled Nanofibre Templates. Nat. Nanotechnol. 2007, 2, 765-769.

(38) Dong, X. M.; Kimura, T.; Revol, J.-F.; Gray, D. G. Effects of Ionic Strength on the Isotropic-Chiral Nematic Phase Transition of Suspensions of Cellulose Crystallites. Langmuir 1996, 12, 2076-2082.

(39) Biyani, M. V.; Foster, E. J.; Weder, C. Light-Healable Supramolecular Nanocomposites Based on Modified Cellulose Nanocrystals. ACS Macro Lett. 2013, 2, 236-240.

(40) Haghpanah, J. S.; Tu, R.; Da Silva, S.; Yan, D.; Mueller, S.; Weder, C.; Foster, E. J.; Sacui, I.; Gilman, J. W.; Montclare, J. K. Bionanocomposites: Differential Effects of Cellulose Nanocrystals on Protein Diblock Copolymers. Biomacromolecules 2013, 14, 43604367.

(41) Lenz, A. G.; Karg, E.; Lentner, B.; Dittrich, V.; Brandenberger, C.; Rothen-Rutishauser, B.; Schulz, H.; Ferron, G. A.; Schmid, O. A Dose-Controlled System for Air-Liquid Interface Cell Exposure and Application to Zinc Oxide Nanoparticles. Part. Fibre Toxicol. 2009, 6, 32.

(42) Michen, B.; Balog, S.; Rothen-Rutishauser, B.; Petri-Fink, A.; Vanhecke, D., TEM Sample Preparation of Nanoparticles in Suspensions. Understanding the Formation of Drying Artefacts. Imaging Microsc. 2014, http://www.imaging-git.com/science/ electron-and-ion-microscopy/tem-sample-preparation-nanoparticlessuspensions.

(43) Schneider, C. A.; Rasband, W. S.; Eliceiri, K. W. NIH Image to ImageJ: 25 Years of Image Analysis. Nat. Meth. 2012, 9, 671-675. 
(44) Vincent, P. D. Nanoparticle Tracking Analysis (NTA) Characterisation of nanomaterials for toxicological assessment. Chim. Oggi 2012, 30, 26-30.

(45) Blank, F.; Rothen-Rutishauser, B. M.; Schurch, S.; Gehr, P. An Optimized in Vitro Model of the Respiratory Tract Wall to Study Particle Cell Interactions. J. Aerosol Med. 2006, 19, 392-405.

(46) Rothen-Rutishauser, B. M.; Kiama, S. G.; Gehr, P. A ThreeDimensional Cellular Model of the Human Respiratory Tract to Study the Interaction with Particles. Am. J. Respir. Cell Mol. Biol. 2005, 32, 281-289.

(47) Lehmann, A.; Brandenberger, C.; Blank, F.; Gehr, P.; RothenRutishauser, B. A 3D model of the human epithelial airway barrier. In Alternatives to Animal Testing; Yamush, M. L., Langer, R. S., Eds.; Artech House: Norwood, MA, 2010; pp 239-260.

(48) Steiner, S.; Mueller, L.; Popovicheva, O. B.; Raemy, D. O.; Czerwinski, J.; Comte, P.; Mayer, A.; Gehr, P.; Rothen-Rutishauser, B.; Clift, M. J. D. Cerium Dioxide Nanoparticles Can Interfere with the Associated Cellular Mechanistic Response to Diesel Exhaust Exposure. Toxicol. Lett. 2012, 214, 218-225.

(49) Adamis, Z.; Tatrai, E.; Honma, K.; Ungvary, G. In Vitro and in Vivo Assessment of the Pulmonary Toxicity of Cellulose. J. Appl. Toxicol. 1997, 17, 137-141.

(50) Cullen, R. T.; Miller, B. G.; Jones, A. D.; Davos, J. M. G. Toxicity of Cellulose Fibres. Ann. Occup. Hyg. 2002, 46, 81-84.

(51) de Lima, R.; Mattoso; Feitosa; Maruyama; Barga; Yamawaki; Vieira; Teixeira; Fraceto, L. Evaluation of the Genotoxicity of Cellulose Nanofibers. Int. J. Nanomed. 2012, 3555-3565.

(52) Hanif, Z.; Ahmed, F. R.; Shin, S. W.; Kim, Y.-K.; Um, S. H. Sizeand Dose-Dependent Toxicity of Cellulose Nanocrystals (CNC) on Human Fibroblasts and Colon Adenocarcinoma. Colloids Surf., B 2014, 119, 162-165.

(53) Jeong, S. I.; Lee, S. E.; Yang, H.; Jin, Y. H.; Park, C. S.; Park, Y. S. Toxicologic Evaluation of Bacterial Synthesized Cellulose in Endothelial Cells and Animals. Mol. Cell. Toxicol. 2010, 6, 373-380.

(54) Milton, D. K.; Godleski, J. J.; Feldman, H. A.; Greaves, I. A. Toxicity of Intratracheally Instilled Cotton Dust, Cellulose and Endotoxin. Am. Rev. Respir. Dis. 1990, 142, 184-192.

(55) Muhle, H.; Ernst, H.; Bellmann, B. Investigation of the Durability of Cellulose Fibres in Rat Lungs. Ann. Occup. Hyg. 1997, 41 (Suppl.1), 184-188.

(56) Pereira, M. M.; Raposo, N. R. B.; Brayner, R.; Teixeira, E. M.; Oliveira, V.; Quintão, C. C. R.; Camargo, L. S. A.; Mattoso, L. H. C.; Brandão, H. M. Cytotoxicity and Expression of Genes Involved in the Cellular Stress Response and Apoptosis in Mammalian Fibroblast Exposed to Cotton Cellulose Nanofibers. Nanotechnology 2013, 24, 075103.

(57) Tatrai, E.; Brozik, M.; Adamis, Z.; Meretey, K.; Ungvary, G. In Vivo Pulmonary Toxicity of Cellulose in Rats. J. Appl. Toxicol. 1996, $16,129-135$.

(58) Warheit, D. B.; Snajdr, S. I.; Hartsky, M. A.; Frame, S. R., Twoweek inhalation study in rats with cellulose fibers. Advances in the Prevention of Occupational Respiratory Diseases; Elsevier Science: Amsterdam, 1998; Vol. 1153, pp 579-582.

(59) Yanamala, N.; Farcas, M. T.; Hatfield, M. K.; Kisin, E. R.; Kagan, V. E.; Geraci, C. L.; Shvedova, A. A. In Vivo Evaluation of the Pulmonary Toxicity of Cellulose Nanocrystals: A Renewable and Sustainable Nanomaterial of the Future. ACS Sustainable Chem. Eng. 2014, 2, 1691-1698.

(60) Ochs, M.; Weibel, E., Functional design of the human lung for gas exchange. In Fishman's Pulmonary Diseases and Disorders, 4th ed.; Fishman, A. P., Elias, J. A., Fishman, J. A., Grippi, M. A., Senior, R. M., Pack, A. I., Eds.; McGraw Hill: New York, 2008.

(61) Rastogi, R.; Kaushal, R.; Tripathi, S. K.; Sharma, A. L.; Kaur, I.; Bharadwaj, L. M. Comparative Study of Carbon Nanotube Dispersion Using Surfactants. J. Colloid Interface Sci. 2008, 328, 421-428.

(62) Vaisman, L.; Wagner, H. D.; Marom, G. The Role of Surfactants in Dispersion of Carbon Nanotubes. Adv. Colloid Interface Sci. 2006, 128-130, 37-46.
(63) Müter, D.; Bock, H. Interactions between Nanofibers in FiberSurfactant Suspensions: Theory of Corresponding Distances. Phys. Rev. Lett. 2014, 112, 128301.

(64) Gardner, D. J.; Oporto, G. S.; Mills, R.; Samir, M. A. S. A. Adhesion and Surface Issues in Cellulose and Nanocellulose. J. Adhes. Sci. Technol. 2008, 22, 545-567.

(65) Chortarea, S.; Clift, M. J. D.; Endes, C.; Wick, P.; Petri-Fink, A.; Rothen-Rutishauser, B. Repeated Exposure to Carbon NanotubeBased Aerosols Does Not Affect the Functional Properties of a 3D Human Epithelial Airway Model. Nanotoxicology 2015, Feb 20, 1-11.

(66) Mahmoud, K. A.; Mena, J. A.; Male, K. B.; Hrapovic, S.; Kamen, A.; Luong, J. H. T. Effect of Surface Charge on the Cellular Uptake and Cytotoxicity of Fluorescent Labeled Cellulose Nanocrystals. ACS Appl. Mater. Interfaces 2010, 2, 2924-2932. 